\title{
Technical note \\ The analysis of 74 years of rainfall recorded by the Irwins on two farms south of Potchefstroom
}

\author{
SD Lynch*, JT Zulu, KN King and DM Knoesen \\ School of Bioresources Engineering and Environmental Hydrology, University of Natal, Scottsville 3209, South Africa
}

\begin{abstract}
Rainfall records for three rain gauges on the farm Limerick and three rain gauges on the farm Mealielands were recorded from 1924 until 1999 by Mr DJ Irwin and his son Mr NG Irwin. The observations from these two nests of rain gauges are used to analyse the trends in rainfall measurements over time and to analyse the correlation of rainfall measurements between these rain gauges. The results presented in this report highlight the fact that the observations of rainfall are different to one another in many cases, indicating that care should be taken when selecting a rain gauge to represent the rainfall over a particular area. Analysis of the annual totals of rainfall has also found that at least 15 years of observations are required to determine a representative MAP value. The analysis of the monthly rainfall data also indicates that the rainy season commences in November and ends towards the end of April. A study of the extreme daily rainfall events shows that many of the storms are localised and are confined to an area around the rain gauges. The length of the droughts on these two farms are not as long as the national figures which would indicate that more point rainfall estimates are required to understand fully the spatial extent of a drought.
\end{abstract}

\section{Introduction}

The Irwin family, Mr DJ Irwin and his son, Mr NG Irwin, recorded climate data that includes daily rainfall, temperature and frost measurements on two farms, Limerick and Mealielands, south of Potchefstroom and roughly $25 \mathrm{~km}$ west of the Vredefort dome (Visser, 1989), dating back to 1924 . The three rain gauges at Limerick are 0436577CP, 0436577DP and 0436577EP and the three at Mealielands are 0436577FP, 0436577GP and 0436577HP and the locations are presented in Fig 1. The six rain gauges are within $6 \mathrm{~km}$ of each other with an altitude range of approximately $100 \mathrm{~m}$. Mr DJ Irwin farmed maize on Limerick and $\mathrm{Mr}$ NG Irwin diversified and included crops such as sunflowers and groundnuts when he took over the farming on Limerick and when he acquired the farm Mealielands in the 1950s.

\section{Rainfall data source}

Mr Neville Irwin contacted the School of Bioresources Engineering and Environmental Hydrology (BEEH) at the University of Natal in the early 1980s and agreed to make the Limerick rainfall data available to a Water Research Commission (WRC)-funded project entitled Mapping Mean Annual and Other Rainfall Statistics over Southern Africa (Dent et al., 1988). This project utilised the data from Limerick $(0436577 \mathrm{CP})$ only at a monthly and annual time step as this was all that was required at the time. He then made contact with BEEH in 2000 and supplied them with the complete set of climate observations of the 6 sites that were compiled by

* To whom all correspondence should be addressed. 푱(033) 260-5412; fax: (033) 260-5818; e-mail: 1ynchs@nu.ac.za Received 3 May 2001; accepted in revised form 29 August 2001. himself and his father. These daily observations are to be incorporated into a current WRC-funded project entitled The Development of an Improved Gridded Database of Annual, Monthly and Daily Rainfall. A copy of the records for 18 November 1999 are presented in Fig. 2 to highlight the diligence of the Irwin family in recording climatic data. The last entry marks the date on which Mr Neville Irwin retired after 45 years of farming.

\section{The analysis of rainfall data}

The current WRC-funded project (The Development of an Improved Gridded Database of Annual, Monthly and Daily Rainfall) has afforded the authors the opportunity to develop a suite of computer programs to analyse the distribution and behaviour of rainfall across Southern Africa. These six rainfall data sets that were recorded by the same persons and that are within a few kilometres apart will be used in this report to validate and verify the methodology that is applied to the Southern African rainfall database that 


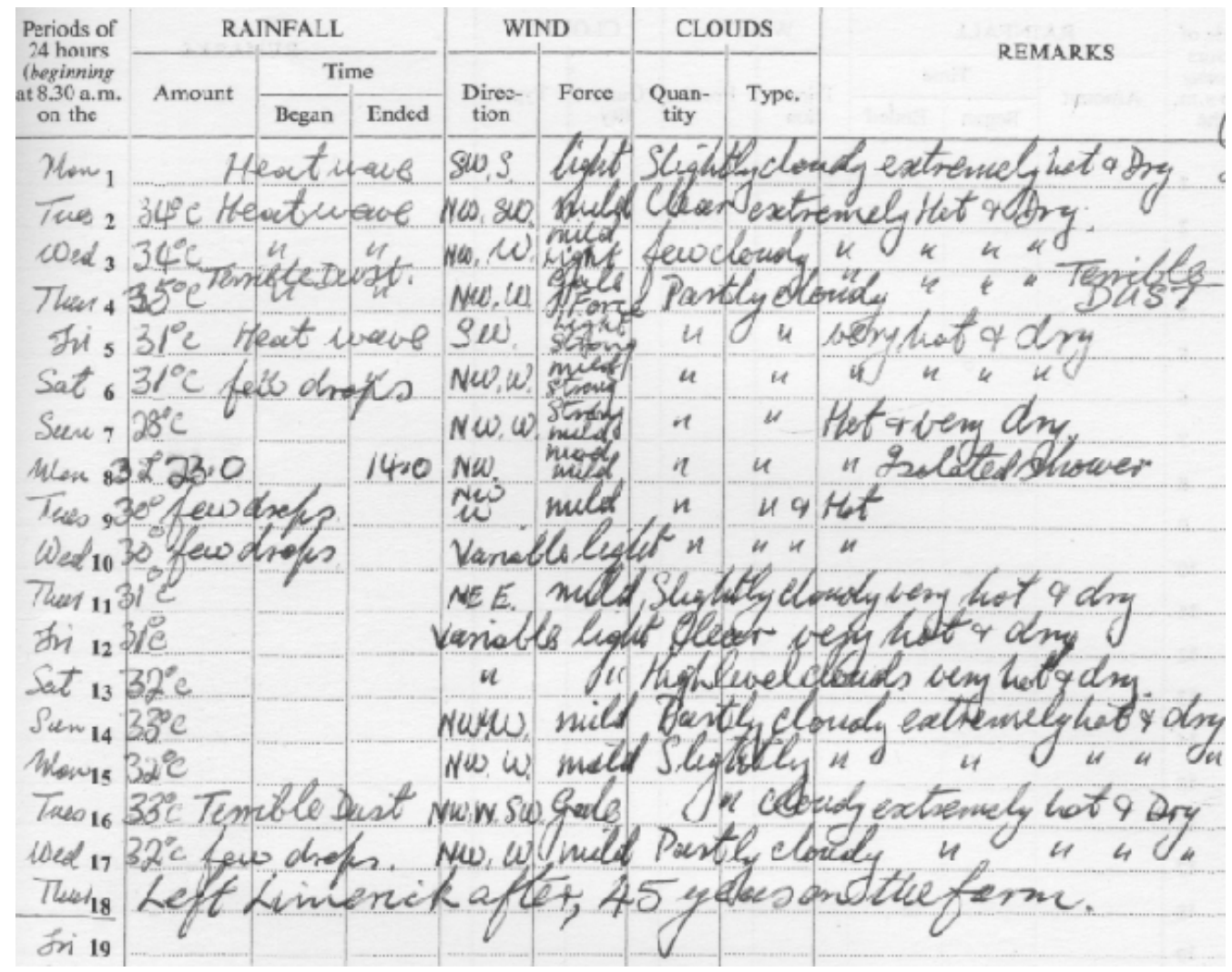

Figure 2

Copy of the records of Limerick for November 1999

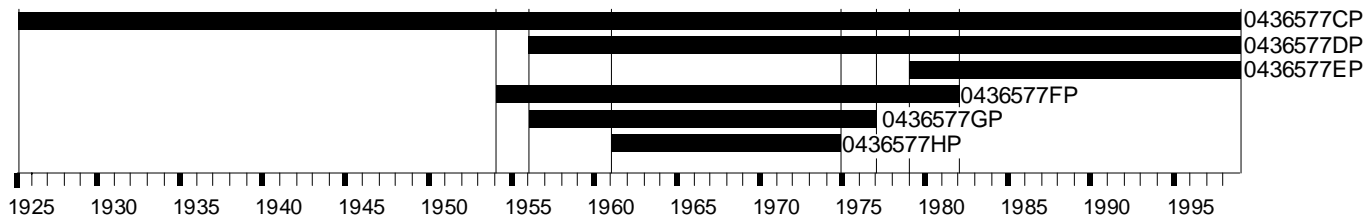

Figure 3

Period of rainfall measurements on Limerick and Mealielands

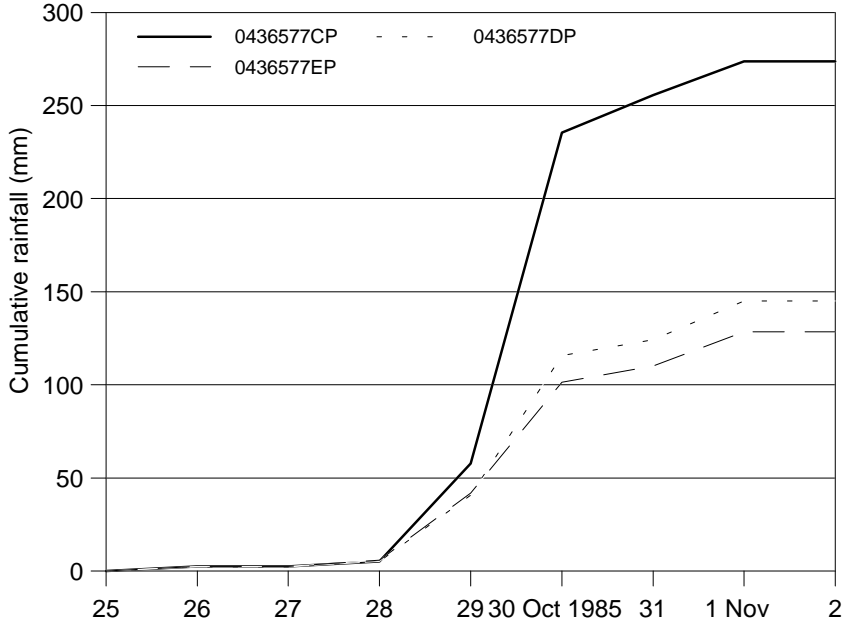

Figure 4

The rainfall amounts, for Limerick, for the period surrounding 30 October 1985

contains more than 110 million observations for roughly 12000 rain gauges.

The longest recording rain gauge, $0436577 \mathrm{CP}$, at Limerick has data from 1 April 1924 until 17 November 1999 with 15 unrecorded or missing values during July 1939 when Mr DJ Irwin was away on holiday according to the notes in the hand-written records. A manual in-filling approach of using neighbouring rainfall data was used to estimate these missing values so that the data set has a complete record of 74 years. A similar approach was followed to in-fill the missing values of the five other rainfall data sets and the period of rainfall observations are presented in Fig. 3.

The appeal of these data sets is that they were recorded by the same person and because of their proximity to each other they can be used to analyse the data by using a host of comparison and descriptive statistical techniques. When combining all six rainfall data sets into one data set, there is a total of 76916 values of which 114 are missing, 60910 are zero and 15892 are rainfall amounts greater than zero.

The highest daily rainfall amount of $178 \mathrm{~mm}$ for the Limerick nest of rain gauges was recorded on 30 October 1985. All three of the Limerick rain gauges were operative on this day and a period surrounding this date are presented in Fig. 4 in the form of daily and cumulative rainfall amounts. On 23 February 1976 five of the six rain gauges were active and measured daily rainfall in excess of $60 \mathrm{~mm}$. The data presented in Fig. 5, for February 1976, highlight the problem that one is faced with when measuring rainfall using a standard rain gauge at sites that are in close proximity of one another. The extreme values for 23 February 1976 vary from a low of $66 \mathrm{~mm}$ to a high of $114 \mathrm{~mm}$, whereas the cumulative totals for the month vary between $134 \mathrm{~mm}$ and $180 \mathrm{~mm}$.

When analysing the data from all six rain gauges as one data set, 


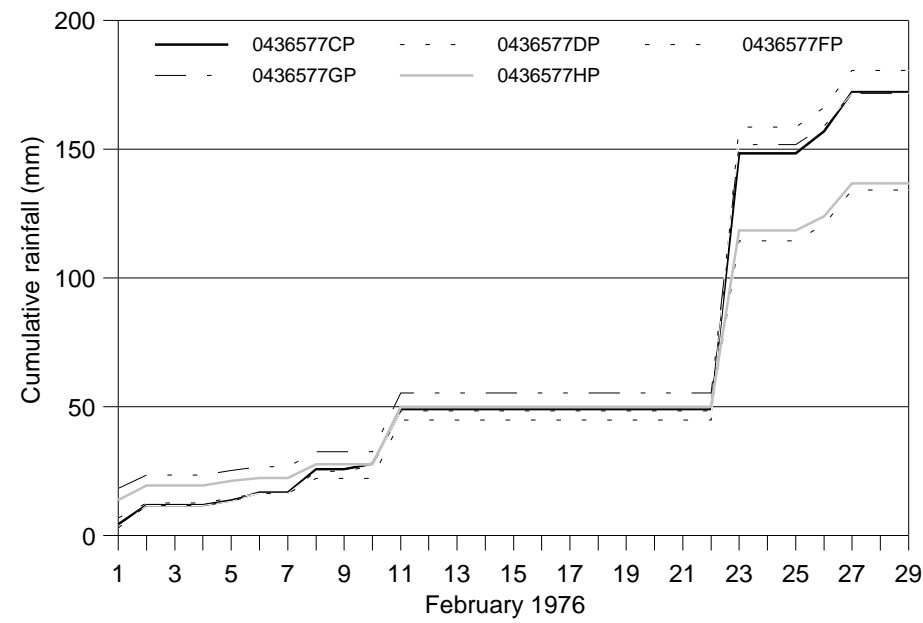

Figure 5

The rainfall amounts for the five rain gauges that were active during February 1976

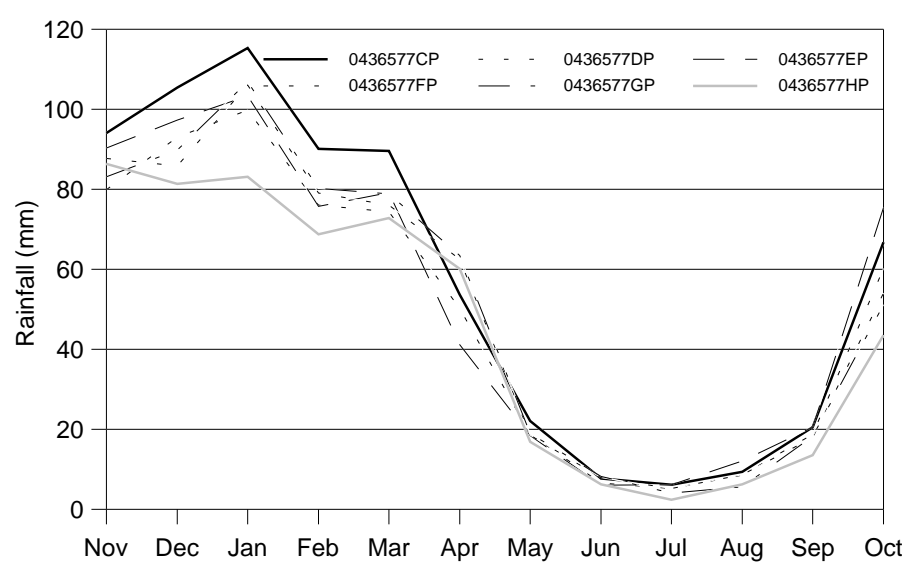

Figure 6

Monthly means of rainfall at Limerick and Mealielands

one finds that roughly $80 \%$ of the time a value of $0 \mathrm{~mm}$ is recorded, and for $10 \%$ of the time values of less than $5 \mathrm{~mm}$ are recorded (Table 1). This implies that only $10 \%$ of the daily rainfall that is measured is greater than $5 \mathrm{~mm}$.

People who enjoy outdoor events often believe that rainfall only occurs on a weekend. Analysis of the daily rainfall data, Table 2 , however, disproves this theory. If one were to look at the data in Table 2 with a fine tooth-comb, one could conclude that the best chance of no rain would be on a Sunday and the best chance of rain occurring would be on a Wednesday. This would, however, fall into the "using statistics for the sake of using statistics" category.

Further analysis of the data, Limerick $0436577 \mathrm{CP}$, reveals that the probability of more than $5 \mathrm{~mm}$ of rain recorded on a day occurs on roughly 37 days of the year, $50 \%$ of the time and a more detailed analysis is presented in Table 3 .

The daily rainfall records are also analysed to determine when the rainy season commences and when it ends. The rainy season, on average, starts in November and ends towards the latter part of April with an approximate period of 6 months. The yield of a crop is related to the amount of rain that falls during some critical period of growth. A probability of roughly $85 \%$ exists for the area surrounding the Irwin farms to receive more than $50 \mathrm{~mm}$ of rainfall over 70 and $100 \mathrm{~d}$ between October and December (Zucchini and Adamson, 1984). The longest recording rain gauge at Limerick
Table 1

Frequency analysis of the amount of rainfall recorded over time

\begin{tabular}{|l|c|c|}
\hline $\begin{array}{l}\text { Rainfall } \\
\text { (mm) }\end{array}$ & $\begin{array}{c}\% \text { of } \\
\text { days }\end{array}$ & $\begin{array}{c}\text { Cumulative } \\
\text { total (\%) }\end{array}$ \\
\hline Zero & 79.308 & 79.308 \\
$0-5$ & 11.149 & 90.457 \\
$5-10$ & 3.767 & 94.224 \\
$10-25$ & 4.277 & 98.501 \\
$25-50$ & 1.281 & 99.782 \\
$50-100$ & 0.211 & 99.993 \\
$100-200$ & 0.007 & 100.000 \\
\hline
\end{tabular}

\begin{tabular}{|l|l|l|}
\hline \multicolumn{3}{|c|}{ Table 2} \\
Rainfall per day of the week analysis \\
\hline & \multicolumn{2}{|c|}{ Number of days with } \\
& $\mathbf{0 ~} \mathbf{~ m m}$ & $>\mathbf{~ m m}$ \\
\hline \multirow{2}{*}{ Sunday } & 8791 & 2179 \\
Monday & 8695 & 2282 \\
Tuesday & 8697 & 2279 \\
Wednesday & 8632 & 2339 \\
Thursday & 8658 & 2313 \\
Friday & 8675 & 2292 \\
Saturday & 8762 & 2208 \\
\hline
\end{tabular}

\begin{tabular}{|c|c|c|}
\hline \multicolumn{4}{|c|}{ Table 3} \\
Number of days of the year that a certain \\
amount of rainfall is exceeded
\end{tabular}

(0436577CP) has the longest continuous period, $145 \mathrm{~d}$, in which zero rainfall was recorded and this occurred between 14 May 1937 and 5 October 1937 (Table 4). All three rain gauges at Mealielands, on the other hand, recorded 10 continuous days of rainfall during the period 11-20 November 1963.

Only the two rain gauges at Limerick $(0436577 \mathrm{CP}$ and 0436577DP) have more than 40 years of complete annual totals. A moving window approach (Lynch and Dent, 1990) is applied to the data and concludes that 15 years of records are sufficient to produce a MAP value that is within $10 \%$ of the long-term MAP, $90 \%$ of the time (Table 5). A quasi 20-year oscillation in rainfall trends was determined for the north-eastern part of South Africa (Tyson and Dyer, 1975), whereas the results in Table 5 are produced for single rain gauges. 


\begin{tabular}{|c|c|c|c|c|c|c|}
\hline \multicolumn{7}{|c|}{$\begin{array}{c}\text { Table } 4 \\
\text { Longest period in days without and with rain }\end{array}$} \\
\hline & \multicolumn{3}{|c|}{ Without rain } & \multicolumn{3}{|c|}{ With rain } \\
\hline & Start & End & $\begin{array}{l}\text { Length } \\
\text { (days) }\end{array}$ & Start & End & $\begin{array}{l}\text { Length } \\
\text { (days) }\end{array}$ \\
\hline 0436577CP & $14 / 5 / 1937$ & $5 / 10 / 1937$ & 145 & $8 / 5 / 1950$ & $18 / 5 / 1950$ & 11 \\
\hline 0436577DP & $7 / 5 / 1995$ & $25 / 8 / 1995$ & 111 & $16 / 1 / 1958$ & 24/1/1958 & 9 \\
\hline 0436577EP & $8 / 5 / 1980$ & $27 / 8 / 1980$ & 112 & $21 / 11 / 1981$ & 28/11/1981 & 8 \\
\hline 0436577FP & $8 / 5 / 1980$ & $27 / 8 / 1980$ & 112 & $11 / 11 / 1963$ & $20 / 11 / 1963$ & 10 \\
\hline 0436577GP & $10 / 5 / 1962$ & $24 / 8 / 1962$ & 107 & $11 / 11 / 1963$ & $20 / 11 / 1963$ & 10 \\
\hline 0436577HP & $10 / 5 / 1962$ & $24 / 8 / 1962$ & 107 & $11 / 11 / 1963$ & $20 / 11 / 1963$ & 10 \\
\hline
\end{tabular}

amounts for the period 1961 until 1975 for the 5 rain gauges (Table 6) also portray the variation that is displayed in the long-term statistics.

There exists a reasonable period of overlap in the time that the rainfall was recorded for most of the stations (Fig. 3). The nest of rain gauges at Limerick have at least 20 years of overlap and the nest of rain gauges at Mealielands have an overlap period of at least 15 years. There is also an overlap period of 29 years between $0436577 \mathrm{CP}$ at Limerick and 0436577FP at Mealielands.

The rainfall that is measured at

\begin{tabular}{|c|c|c|}
\hline \multicolumn{3}{|c|}{$\begin{array}{l}\text { Table } 5 \\
\text { Percentage error, } 90 \% \text { of the time, } \\
\text { that is made when using a shorter } \\
\text { length of records to determine } \\
\text { the MAP }\end{array}$} \\
\hline \multirow{2}{*}{$\begin{array}{l}\text { Record } \\
\text { length } \\
\text { (years) }\end{array}$} & \multicolumn{2}{|c|}{ Percentage error } \\
\hline & 0436577CP & 0436577DP \\
\hline 5 & 21.0 & 21.1 \\
\hline 10 & 13.8 & 14.7 \\
\hline 15 & 10.6 & 9.6 \\
\hline 20 & 8.8 & 7.3 \\
\hline 25 & 8.8 & 7.3 \\
\hline 30 & 8.3 & 5.6 \\
\hline 35 & 7.1 & 3.8 \\
\hline
\end{tabular}

Limerick (0436577CP) is predominantly higher than the rainfall that is measured at the other rain gauges. The correlation between the three rain gauges at Mealielands, however, suggests that there are factors that affect the volumes of rainfall that are measured. The rainfall at Limerick ( $0436577 \mathrm{CP})$ is, on average, 1.25 times higher than the rainfall at the other two rain gauges (0436577DP, 0436577EP). The two rain gauges at Mealielands (0436577FP, $0436577 \mathrm{GP}$ ) have similar rainfall amounts, whereas $0436577 \mathrm{FP}$ generally records more rainfall than $0436577 \mathrm{HP}$.

The annual totals of rainfall for the period 1954 until 1998 (Fig. 7) present the variation in rainfall that is measured on these two farms. The rainfall at Limerick (0436577CP) is noticeably higher than rainfall recorded at the other sites. The annual totals of rainfall at Limerick $(0436577 \mathrm{CP})$ appear to be gradually increasing over time (Fig. 8) and this could possibly be attributed to the global temperature rise in the Southern hemisphere (National Defense Univ., 1978; Burroughs, 1991). The increase in annual rainfall measurements is apparent when viewing the 5-year moving average filter that is applied to the data (Fig. 8). Kriel (1977) states that annual rainfall totals are not random events, but there are definite trends

Table 6

Selected statistics determined using the complete annual rainfall totals

\begin{tabular}{|l|c|c|c|c|c|c|}
\hline & 0436577CP & 0436577DP & 0436577EP & 0436577FP & 0436577GP & 0436577HP \\
\hline Minimum & 404 & 311 & 388 & 352 & 348 & 256 \\
Maximum & 1140 & 915 & 920 & 887 & 846 & 722 \\
Mean & 684 & 592 & 642 & 601 & 596 & 527 \\
Mean (1961-1975) & 646 & 538 & $\mathrm{n} / \mathrm{a}$ & 589 & 583 & 527 \\
Median & 658 & 597 & 613 & 608 & 586 & 520 \\
Median (1961-1975) & 640 & 585 & $\mathrm{n} / \mathrm{a}$ & 597 & 585 & 520 \\
St Dev & 177 & 141 & 150 & 115 & 123 & 124 \\
\%CV & 26 & 24 & 23 & 19 & 21 & 24 \\
Years & 74 & 43 & 20 & 29 & 22 & 15 \\
Skew & 0.7 & 0.3 & 0.1 & 0.1 & 0.1 & -0.3 \\
\hline
\end{tabular}
with substantial groupings of dry and wet years and these trends are visible in Figs.7and 8. PrestonWhyte and Tyson (1988) found that noticeable quasi-periodic rainfall oscillations occur after 1968 in the summer rainfall region of South Africa and this trend is visible in the annual totals of rainfall at Limerick (Fig. 8).

The original rainfall records also contain many interesting comments regarding folklore as to the magnitude of rainfall totals. A belief that two moons in a month bring good rains has long been held, but this has since been revealed to be

The statistics calculated using the annual rainfall measurements (Table 6) highlight, once again, the variability in the observed rainfalls that are measured at rain gauges that are in close proximity to one another. The MAP values range between $527 \mathrm{~mm}$ and $684 \mathrm{~mm}$. The median annual precipitation values are similar in magnitude to the MAP values for all the stations and this enforces the theory that the minimum length of record of greater that 15 years is sufficient to produce meaningful results when analysing the data at an annual time step. The mean and median annual precipitation folklore (Visagie, 1966; Marriott, 1981). Lunar cycles comprise $29.5 \mathrm{~d}$ and for a month to have two full moons therein, the occurrence of a full moon needs to fall on the first and last days of that month, making such an occurrence rare. It is widely believed that if a second full moon is apparent within one month, the second moon will be called a blue moon. This has since been said to be untrue and it now appears that a "blue moon" occurs when a solstice-and-equinox defined season has four full moons, as apposed to the usually expected three full moons in a season. The third of 
these four moons is referred to as the blue moon (Rowley et al., 2001). Analysis of the data reveals that there were 31 two-full-moon months, occurring within a total of 29 years, in the 75 recorded rainfall years. Only seven of these occurrences fell strictly in the summer months, yet 18 fell in the general Limerick rainy season. As these were the wet months of the year, rain events in these two full-moon months exceeded the mean monthly rainfall twelve times for rain gauge $0436577 \mathrm{CP}$.

The definition of a drought will vary in accordance with the profession of the person defining it. Hydrologists consider a dry period of time to be a drought when the annual rainfall total falls into a statistically determined percentile of the annual rainfall totals for that period. A farmer, however, might classify a drought as a time in which not enough rain fell in an area to meet the needs of the people living in that area. Bruwer (1990) considers a drought to be severe when two consecutive seasons experience abnormally low rainfall. Droughts are usually associated with prolonged periods of anticyclonic activities over the inland plateau (Dept. Water Affairs and Forestry, 1986) which includes the farms Limerick and Mealielands. Analysis of the driest 33 rd percentile of annual rainfall totals for all six operative rain gauges, reveal that these largely correspond with the nationwide drought periods experienced at that time. From 1960 to 1966 the drought that affected the largest area of the country was recorded. Thus, most of the country was drought-stricken. Mr NG Irwin recorded very dry years during this time, including just over $400 \mathrm{~mm}$ of rain in 1965. The year 1960 was, in fact, a wetter season than usual for Mr Irwin, followed by three average rainfall years. The three years following these, however, were drier than usual. The longest lasting drought experienced by the Irwin family lasted from 1925 to 1933 . Mr DJ Irwin started farming at Limerick in April 1924, and recorded an annual rainfall total of $450 \mathrm{~mm}$ for 1926 and $441 \mathrm{~mm}$ for 1933.1925 was, however, a wetter than usual year at Limerick, followed by three dry years, an average year, and another four drier-than-usual years. These drier years also fall into the driest 33rd percentile of the years on the farm. The drought of 1978 (Dept. Water Affairs and Forestry, 1986), however, was not experienced by the Irwin family.

\section{Discussion and conclusions}

The rainfall records maintained by the Irwin family are unique in the sense that the original records are available for perusal when outliers and discrepancies in the rainfall amounts are found while analysing the data. The ability to contact Mr Neville Irwin has also been of assistance in the interpretation of the results derived from the rainfall measurements. An example being the presence of an Eucalyptus grandis plantation close to $0436577 \mathrm{CP}$ and the fact that this rain gauge is of a different design to the others, according to $\mathrm{Mr}$ Irwin, could explain why this rain gauge records more rainfall than the other two rain gauges on the farm Limerick.

This study has shown that many of the trends that are visible in these localised rainfall data will be lost when the rainfall data are analysed on a country-wide scale. This research, using a small number of rain gauges, will be beneficial to the current WRC project as it has enabled the interpetation of individual records which will not be possible when analysing the complete Southern

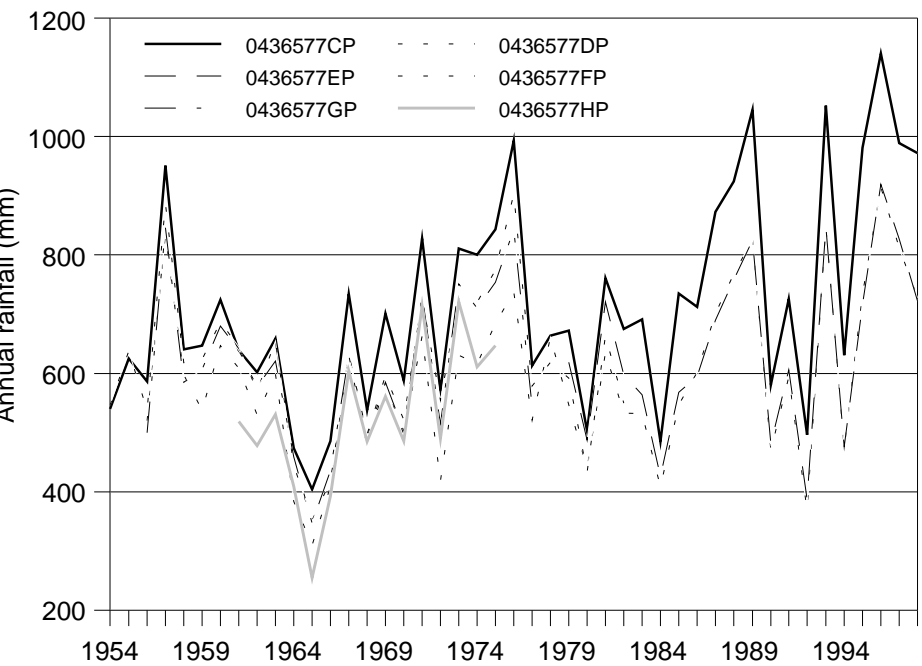

Figure 7

Annual totals of rainfall at Limerick and Mealielands

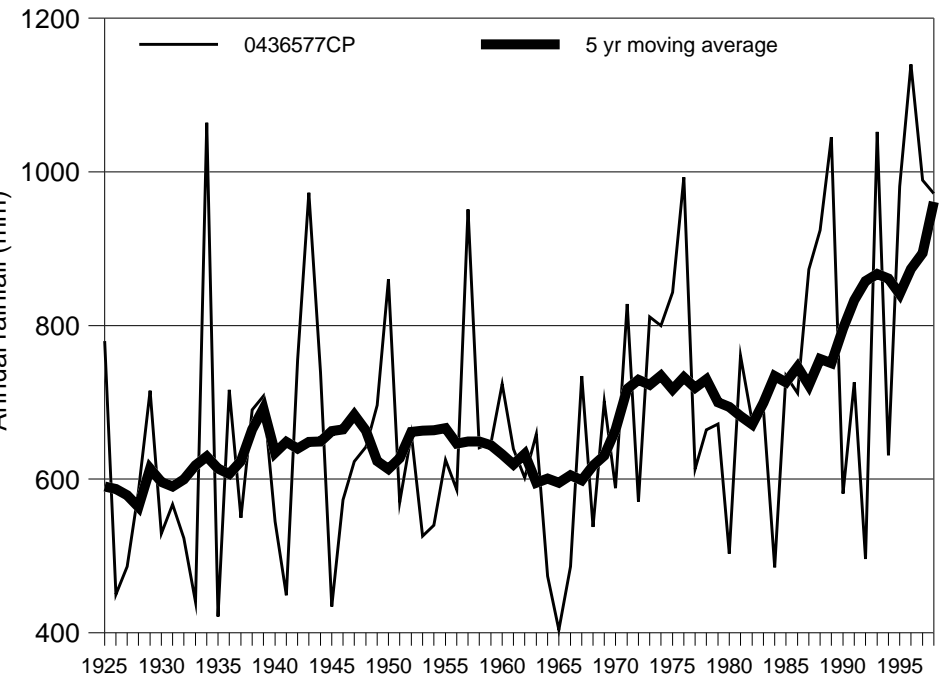

Figure 8

Complete record of annual totals of rainfall at Limerick (0436577CP)

African database which currently has more than 110 million records of observed and in-filled daily rainfall amounts. A suite of computer programs has been developed to assist with analysing the rainfall data and these programs were validated and verified using these small rainfall data sets.

Contained within the original rainfall data are references to beliefs that the Irwin family held regarding climate and other occurrences. This includes beliefs regarding volcanoes in Bali and the Andes, as well as links between the rainfall and months in which two full moons occurred. In March and May 1963, the Agung Volcano in Bali erupted, killing roughly 1500 people. As a result, "beautiful red sunsets" were apparent at Limerick from April until July. It is also apparent from the remarks contained within the climate records that farming was profitable as Mr DJ Irwin purchased a new car roughly every 3 years and the Irwin family went on holiday annually, including a two-month holiday to South America in July 1957.

The drought analysis shows that, although a specific region 
may be experiencing a drought as a whole, not every site within that region will necessarily experience the effects of the drought Therefore, any monetary compensation given to farmers for drought losses should be site-specific rather than region-specific. The rainfall data for Limerick (0436577CP) are invaluable when analysing the extent of the drought in an area as it includes continuous daily rainfall records dating back to 1924. It is important that rainfall records that are maintained by the public are captured into a national rainfall database.

\section{Acknowledgements}

Mr Neville Irwin is thanked for making the Limerick and Mealielands data available to this project. The WRC is thanked for their financial support in this three-year rainfall database development project. The dedication of all observers of climatic data are acknowledged.

\section{References}

BRUWER JJ (1990) Drought policy in the Republic of South Africa. Proc. SARCCUS Workshop on Drought, June 1989. Southern African Regional Commission for the Conservation and Utilisation of the Soil, Pretoria. South Africa.

BURROUGHS WJ (1991) Watching the World's Weather. Cambridge Univ. Press, Cambridge, New York, United States of America.

DENT MC, LYNCH SD and SCHULZE RE (1988) Mapping Mean Annual and Other Rainfall Statistics over Southern Africa. Univ. of Natal, Dept. Agric. Eng., ACRU Report 27. WRC. Report No 109/1/89.
DEPARTMENT OF WATER AFFAIRS AND FORESTRY (1986) Management of the Water Resources of the Republic of South Africa. Pretoria, South Africa. 1.4-1.5.

Kriel JP (1971) Rainfall trends in South Africa. Letter to the Editor. S. Afr. J. Sci. 67 65-67.

LYNCH SD and DENT MC (1990) Appropriate record lengths for the estimation of mean annual and mean monthly precipitation in southern Africa. Water SA 16 93-98.

MARRIOTT PJ (1981) Red Sky at Night, Shepherd's Delight? : Weather Lore of the English Countryside. Oxford Books. London, United Kingdom.

NATIONAL DEFENSE UNIVERSITY (1978) Climate Change to the Year 2000: A Survey of Expert Opinion. Fort Lesley J. McNair, Washington, DC, United States of America.

PRESTON-WHYTE RA and TYSON PD (1988) The Atmosphere and Weather of Southern Africa. Oxford University Press, Cape Town, South Africa.

ROWLEY M, ROWLEY G and ROWLEY W (2001) Blue Moon: The Facts. (www.booty.demon.co.uk/metinfo/bluemoon.htm)

TYSONPD and DYER TGJ (1975) Mean annual fluctuations of precipitation in the summer rainfall region of South Africa. S. Afr. Geogr. J. 57 104-110.

VISAGIE PJ (1966) Precipitation in South Africa and lunar phase. J. Geophys. Res. 7114 3345-3350.

VISSER DJL (1989) Explanation of the 1:1 000000 Geological Map (4th edn.) 1984. Dept. of Mineral and Energy Affairs, Pretoria, South Africa.

ZUCCHINI W and ADAMSON PT (1984) The Occurrence and Severity of Droughts in South Africa. WRC Report No 91/1/84. 